\title{
Administration of Systemic Antibiotics for Dental Treatment in Kosovo Major Dental Clinics: A National Survey
}

\author{
Lirim Mustafa ${ }^{1}$ Hilmi Islami ${ }^{2}$ Ivana Sutej ${ }^{3}$ \\ ${ }^{1}$ Department of Health Management - Economy, School of Dental \\ Medicine, University of Zagreb, Zagreb, Croatia \\ 2 Pharmacology Department, Medical Faculty, University “Hasan \\ Prishtina", Kosovo, Republic of Kosovo \\ ${ }^{3}$ Department of Pharmacology, School of Dental Medicine, University \\ in Zagreb, Croatia \\ Eur J Dent 2022;16:430-436. \\ Address for correspondence Ivana Sutej, Department of \\ Pharmacology, School of Dental Medicine, University in Zagreb, \\ Šalata 11, 10000 Zagreb, Croatia (e-mail: isutej@sfzg.hr).
}

\begin{abstract}
Keywords

- antibiotics

- dentistry

- resistance

- prescriptions

Objective Antibiotics misuse and a high level of antibiotics resistance is observed worldwide, but particularly in developing countries. Kosovo in the last decade is facing challenges regarding antimicrobial resistance. The purpose of the present study was to investigate patterns of antibiotics prescriptions of dentists in Kosovo's major dental clinics.

Materials and Methods For Kosovo's prescribing pattern, data collection was obtained from 10 Regional Dental Clinics and a Tertiary Health Center regarding patients who were prescribed antibiotics in the years 2015 to 2019. Data analysis was performed by using descriptive statistics and was processed by using MS Excel.

Results Most prescribed antibiotic during the observed period from 2015 to 2019 in Kosovo was amoxicillin, although a drastic increase of amoxicillin with clavulanic acidas a broad-spectrum antibiotic-is observed. The trend of antibiotics use in tertiary health institutions is in an overall decrease in Kosovo with an exception in the year 2017. Despite this overall decrease, inconsistency in prescribing is observed when the pattern is analyzed for each region separately. The highest number of patients in health care dental clinics received antibiotics for maxilla-related health conditions and the lowest number of them for oncologic ones.

Conclusion The patterns of antibiotics prescriptions by dental practitioners in Kosovo during the years 2015 to 2019 are fluctuating. Compared with the global health care standards, the irrational use of antibiotics in dental health care clinics in Kosovo still exist and this issue should be further addressed by respective actors.
\end{abstract}

\section{Introduction}

Antibiotics are a precious medicine for the treatment of spreading bacterial dental infections. Nowadays, the appropriate prescription of antibiotics has become a challenge in most

published online January 11,2022
DOI https://doi.org/ 10.1055/s-0041-1735931. ISSN $1305-7456$ health care systems because different studies have reported that antibiotics are often irrationally overprescribed, which form the basis of antimicrobial resistance. ${ }^{1}$ The extensive utilization of antibiotics in clinical practice has been determined to be a leading factor for the emergence of antibiotic

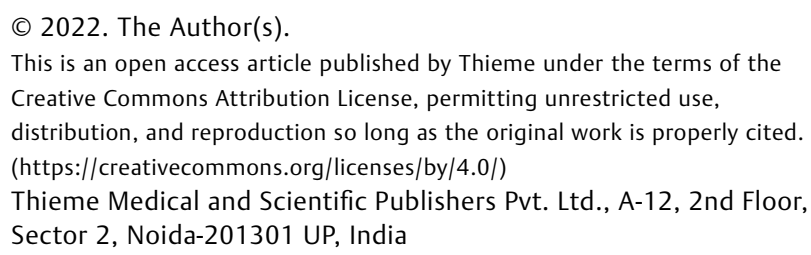


resistance. $^{2}$ Inefficient therapy due to resistance is associated with increasing human suffering, loss of productivity, and often ending with death. Antibiotics misuse and a high level of antibiotics resistance (AMR) are observed particularly in developing countries. Kosovo, a country located in Southeast Europe with a population of 1.7 million inhabitants, is facing some challenges regarding antimicrobial resistance such as limited financial and human resources, over-the-counter sale of antibiotics, and scarcity of clinical guidelines authorized by the Ministry of Health. ${ }^{3}$ Kosovo is two to five times higher for the majority resistance of bacteria and corresponding antibiotics groups compared with the means in European countries. ${ }^{4}$

To address the challenge of antimicrobial resistance, the Ministry of Health in Kosovo adopted (2011-2015) the first National Strategy and Action Plan to Combat Antimicrobial Resistance, which resulted in the surveillance of general antibiotics consumption. ${ }^{3}$ Despite the high level of knowledge of health care professionals and great awareness of antimicrobial resistance, prescribing and dispensing practices were influenced by challenges of access to information on resistance patterns, next line antibiotics, diagnostics, and patient records. ${ }^{5}$ Second National Action Plan for Antimicrobial Resistance was adopted (2019-2021) by the Ministry of Health regarding reports from various researches dealing with resistance occurrence, ${ }^{4,6}$ which was also aimed at improving the monitoring capacity and optimization of antibiotics' use. The latest World Health Organization (WHO) data in 2018 showed that Kosovo made progress in appointing an AMR focal point by the Ministry of Health as well as an intersectoral coordinating mechanism to control AMR. ${ }^{7}$ Also, in 2019, country representatives in a regional workshop held in Belgrade, Serbia reported a significant decrease in antibiotic consumption (25\%). ${ }^{8}$ However, a fully functional AMR reference laboratory with a quality assessment system in place is still missing.

Dental practitioners are frequently prescribing antibiotics for their patients as outpatient care. Among the reasons for the misuse of antibiotics in dentistry are the dentists' desire to avoid clinical complications, the fear to lose patients, and perceived patient pressure. ${ }^{9}$ Recent research studies advocated that dental practitioners should prescribe antibiotics/antimicrobials only for acute orodental conditions, where drainage or debridement is impossible, where there is a local spread of infection, or where systemic upset has occurred, ${ }^{10}$ but not for mere inflammation. ${ }^{11,12}$ Additionally, prophylactic use of antimicrobials ${ }^{13}$ in dental treatment is strictly recommended with special guidelines for suspected systemic infective conditions, such as infective endocarditis ${ }^{14,15}$ and severely immunocompromised patients. The rational and effective prescription of antimicrobial is imperative in dental practice, and it is necessary to implement an antimicrobial prescription monitoring system and an antibiotic administration program. In addition, quality indicators of antibiotic prescription are needed to be continuously updated according to the standards recommended by WHO.

Therefore, the patterns of antibiotics prescription of dentists in Republic of Kosovo major dental clinics are investigated by this research regarding the extent to which and for what reasons they prescribe antibiotics. The purpose of the present study is to investigate patterns of antibiotics prescription of dentists in Kosovo's major dental clinics.

\section{Materials and Methods}

This study consisted of data collection regarding antibiotics use during 2015 to 2019 at major dental clinics in the Republic of Kosovo. Data collection based on Point Prevalence Survey (PPS) study was performed in 10 regional Dental Clinics and a Tertiary Health Center. Data collection was performed by the author of this study in collaboration with the clinics' experienced staff after ethical approval in May 2019 by the management board of the hospitals and University Clinical Service of Kosovo by app. no. 830/2. Ethical approval for collaboration in research was granted by the Ethic committee of the School of Dental Medicine University in Zagreb 05-PA-30-VII-5/2019.

\section{Data Collection}

Patients' forms were designed based on PPS methodology and contain information on identification of the patients' number, year, age, gender, diagnosis, generic name of the drug used, dosage, the single-dose administered in units, and duration of the treatment. The patient form is developed by the European Antibiotics Use Surveillance ${ }^{16}$ and Antibiotics Resistance and Description of European Children. ${ }^{17}$

Data were gathered and analyzed for the University Clinical Dentistry Center of Kosovo in Prishtina; 18 Family Health Care Centers in Prishtina; and 10 Main Centers of Family Medicine in Vushtrri, Prizren, Mitrovice, Obiliq, Ferizaj, Hani i Elezit, Gjilan, Gjakovë, Fushë Kosovë, and Pejë. Inclusion criteria for data collection were completed antibiotic treatment for a relevant disease in dental medicine in mentioned dental clinics during the period from 2015 to 2019. Emergency patients which had received immediate (short) therapy and were directed to the dentist for further treatment were excluded because of the lack of complete documentation.

\section{Antibiotic Utilization Data}

For analysis of the antibiotic utilization data, the defined daily dose (DDD) and the defined daily dose per 1,000 inhabitants per day (DID) formula codes were used to calculate a standardized measure of medicine consumption at the national level. DDD is defined as the assumed average maintenance dose per day for a drug used for its main indication in adults, and this standard value for each drug was obtained from the World Health Organization Collaborating Centre for Drug Statistics Methodology website (https://www.whocc.no/ atc_ddd_index/), and it has become a major assessment tool in the pharmacoepidemiologic studies since it provides a fixed unit of measurement independent of dosage form, package size, or price.

\section{Statistical Analysis}

Quantitative data are analyzed by statistical analysis where data are transformed into numbers, percentages, tables, and diagrammatic representations. Data were entered in MS 
432 Systemic Antibiotics for Dental Treatment Mustafa et al.

Table 1 Antibiotics' prescriptions in dentistry in Kosovo during years 2015 to 2019

\begin{tabular}{|c|c|c|c|c|c|c|c|c|}
\hline Year & $\begin{array}{l}\text { No. of } \\
\text { health } \\
\text { care } \\
\text { centers }\end{array}$ & $\begin{array}{l}\text { No. of } \\
\text { patients } \\
\text { (total) }\end{array}$ & $\begin{array}{l}\text { Most used } \\
\text { antibiotics }\end{array}$ & $\begin{array}{l}\text { No. of } \\
\text { patients }\end{array}$ & DDDs & $\begin{array}{l}\text { DDD/ } \\
1,000 \\
\text { patients/ } \\
\text { year }\end{array}$ & Most common diagnosis & $\begin{array}{l}\text { No. of } \\
\text { patients }\end{array}$ \\
\hline \multirow[t]{3}{*}{2015} & \multirow[t]{3}{*}{11} & \multirow[t]{3}{*}{1,115} & Cefazolin & 235 & 1,175 & 2.88 & KO4.7: Periapical abscess without sinus & 139 \\
\hline & & & Amoxicillin & 177 & 885 & 2.17 & KO4.5: Chronic apical periodontitis & 87 \\
\hline & & & Cefalexin & 139 & 695 & 1.70 & KO4.0: pulpitis & 55 \\
\hline \multirow[t]{3}{*}{2016} & \multirow[t]{3}{*}{16} & \multirow[t]{3}{*}{1,373} & Amoxicillin & 294 & 1,470 & 2.92 & KO4.7: Periapical abscess without sinus & 293 \\
\hline & & & Cefazolin & 190 & 950 & 1.89 & KO4.1: Necrosis of the pulp & 70 \\
\hline & & & Cefalexin & 120 & 600 & 1.19 & KO4.0: Pulpitis & 61 \\
\hline \multirow[t]{3}{*}{2017} & \multirow[t]{3}{*}{17} & \multirow[t]{3}{*}{1,641} & Amoxicillin & 351 & 1,755 & 2.91 & KO4.7: Periapical abscess without sinus & 443 \\
\hline & & & Cefazolin & 255 & 1,275 & 2.11 & KO4.1: Necrosis of the pulp & 122 \\
\hline & & & Amoxiclav & 216 & 1,080 & 1.79 & KO4.5: Chronic apical periodontitis & 76 \\
\hline \multirow[t]{3}{*}{2018} & \multirow[t]{3}{*}{17} & \multirow[t]{3}{*}{1,336} & Amoxiclav & 216 & 1,080 & 2.16 & KO4.7: Periapical abscess without sinus & 349 \\
\hline & & & Cefazolin & 207 & 1,035 & 2.07 & KO4.1: Necrosis of the pulp & 135 \\
\hline & & & Amoxicillin & 74 & 370 & 0.74 & KO4.5: Chronic apical periodontitis & 67 \\
\hline \multirow[t]{3}{*}{2019} & \multirow[t]{3}{*}{17} & \multirow[t]{3}{*}{862} & Amoxiclav & 215 & 1,075 & 3.41 & KO4.7: Periapical abscess without sinus & 210 \\
\hline & & & Amoxicillin & 164 & 820 & 2.59 & KO4.1: Necrosis of the pulp & 109 \\
\hline & & & Cefazolin & 126 & 630 & 1.99 & KO4.5: Periapical abscess without sinus & 32 \\
\hline
\end{tabular}

Abbreviation: DDD, defined daily dose.

Excel database according to the year, number of health care centers, most used antibiotics, most common diagnosis, and number of patients for both of them. The empirical analysis as the basis of this study is used to arrive at the most complete conclusions.

\section{Results}

On average, there were 181 antibiotic prescriptions issued per dentist/annually, with an average number of $47 \%$ of antibiotic prescriptions per patient who used some kind of service in observed dental clinics. For the analyzed period, the average antibiotic utilization by each dentist was 6.5 DDD/1,000 patients/year, with fluctuations between the years 2015 and 2019. The number of dentists in Kosovo in 2019 was 1,500 and the number of dentists increased by $22 \%$ during the observed period. The number of patients that used dental services was on average 1,265 annually with minimal fluctuations. According to a statistical agency report on population estimation, Kosovo had 1,771,604 inhabitants in 2015 and the number increased by $0.59 \%$ in the next 5 years. $^{18,19}$

All data regarding antibiotics prescription in dentistry in Kosovo are presented in -Table $\mathbf{1}$ according to year, number of dental health care centers; number of patients in total, most used antibiotics, number of patients who received them, and most common diagnosis and number of patients who were diagnosed. There was a decrease in utilization observed from 2017 to 2019 in overall antibiotics prescriptions in each of the cities. Results from antibiotics use during the period from 2015 and 2019 are presented in -Table 2 for each city, with Gjilan having a significant descending trend of antibiotics use and Peja having a significant rising trend. More information on the most common diagnosis for each dental center in Kosovo in the years 2015 to 2019 is presented in -Supplementary Tables S1-S5 (available in the online version only).

Among antibacterials, amoxicillin was the most prescribed, averaging $36 \%$ of all antibiotic prescriptions, which followed by cefazolin (34\%), amoxicillin with clavulanic (26\%), and cefalexin (9\%). A trend of high increase in the use of amoxicillin with clavulanic acid was observed from $1.79 \mathrm{DDD} / 1,000$ patients/year to $3.41 \mathrm{DDD} /$ patient/year over 5 years.

\section{Discussion}

The aims of this study were to perform a descriptive analysis and quality assurance of antibiotic prescriptions at major dental clinics in the Republic of Kosovo during 2015 to 2019. The most prescribed antibiotics by results of this study in secondary/tertiary dental health care in Kosovo were amoxicillin (16.7\%), cefazolin (16\%), amoxiclav (10.2\%), and cefalexin (4.09\%). Amoxicillin, as most prescribed, was the first choice in dental infection treatment as is recommended by guidelines. ${ }^{10-12}$ However, authors must warn of the observed trend of a dramatic increase in amoxicillin with clavulanic acid prescription which is occurring in the past 2 years, increasing from 1.16 DID to 3.86 DID. If this trend is to be continued, then the wider spectrum antibiotic will prevail as the first choice leading to new problems regarding microbial resistance. A similar trend in increasing usage of 
Table 2 Most prescribed antibiotics by the region cities and each dental center in Kosovo in 2015 and 2019

\begin{tabular}{|c|c|c|c|c|c|c|c|}
\hline Place & Year & $\begin{array}{l}\text { Most prescribed } \\
\text { antibiotic } 1\end{array}$ & $\begin{array}{l}\text { No. } \\
\text { of rx. }\end{array}$ & $\begin{array}{l}\text { Most prescribed } \\
\text { antibiotic } 2\end{array}$ & $\begin{array}{l}\text { No. } \\
\text { of rx. }\end{array}$ & $\begin{array}{l}\text { Most prescribed } \\
\text { antibiotic } 3\end{array}$ & $\begin{array}{l}\text { No. } \\
\text { of rx. }\end{array}$ \\
\hline \multirow[t]{2}{*}{ UCDCK in Prishtinë } & 2015 & $\begin{array}{l}\text { Amoxicillin }+ \\
\text { clavulanic acid }\end{array}$ & 6 & Amoxicillin & 1 & No data & 1 \\
\hline & 2019 & $\begin{array}{l}\text { Amoxicillin }+ \\
\text { clavulanic acid }\end{array}$ & 63 & Metronidazole & 14 & No data & 1 \\
\hline \multirow[t]{2}{*}{ MCFM in Vushtrri } & 2015 & Amoxicillin & 68 & $\begin{array}{l}\text { Amoxicillin }+ \\
\text { clavulanic acid }\end{array}$ & 19 & Ceftriaxone & 11 \\
\hline & 2019 & Amoxicillin & 26 & $\begin{array}{l}\text { Amoxicillin }+ \\
\text { clavulanic acid }\end{array}$ & 5 & No data & 1 \\
\hline \multirow[t]{2}{*}{ MCFM in Prizren } & 2015 & Amoxicillin & 27 & No data & & No data & I \\
\hline & 2019 & Amoxicillin & 19 & No data & & No data & 1 \\
\hline \multirow[t]{2}{*}{ MCFM for maxille } & 2015 & Cefazolin & 235 & Ampicillin & 63 & Cefalexin & 54 \\
\hline & 2019 & Cefazolin & 126 & $\begin{array}{l}\text { Amoxicillin }+ \\
\text { clavulanic acid }\end{array}$ & 30 & Metronidazole & 21 \\
\hline \multirow[t]{2}{*}{ MCFM in Mitrovice } & 2015 & Cefalexin & 44 & Ceftriaxone & 16 & Amoxicillin & 12 \\
\hline & 2019 & Cefalexin & 26 & Amoxicillin & 16 & $\begin{array}{l}\text { Amoxicillin }+ \\
\text { clavulanic acid }\end{array}$ & 13 \\
\hline \multirow[t]{2}{*}{ MCFM in Ferizaj } & 2015 & Amoxicillin & 31 & No data & & No data & 1 \\
\hline & 2019 & Amoxicillin & 19 & No data & & No data & 1 \\
\hline \multirow[t]{2}{*}{ MCFM in Gjilan } & 2015 & Amoxicillin & 79 & Penicillin G & 45 & Cefalexin & 41 \\
\hline & 2019 & Amoxicillin & 27 & Penicillin G & 5 & $\begin{array}{l}\text { Amoxicillin }+ \\
\text { clavulanic acid }\end{array}$ & 8 \\
\hline \multirow[t]{2}{*}{ MCFM in Fushë Kosovë } & 2015 & Amoxicillin & 22 & Ceftriaxone & 15 & $\begin{array}{l}\text { Amoxicillin }+ \\
\text { clavulanic acid }\end{array}$ & 11 \\
\hline & 2019 & $\begin{array}{l}\text { Amoxicillin }+ \\
\text { clavulanic acid }\end{array}$ & 26 & Ceftriaxone & 19 & Amoxicillin & 16 \\
\hline \multirow[t]{2}{*}{ MCFM in Pejë } & 2015 & $\begin{array}{l}\text { Amoxicillin }+ \\
\text { clavulanic acid }\end{array}$ & 19 & Amoxicillin & 29 & No data & 1 \\
\hline & 2019 & Amoxicillin & 71 & $\begin{array}{l}\text { Amoxicillin }+ \\
\text { clavulanic acid }\end{array}$ & 27 & No data & 1 \\
\hline
\end{tabular}

Abbreviations: MFMC, Main Family Medicine Center; UCDCK, University Clinical Dentistry Centre of Kosovo.

amoxicillin with clavulanic acid was observed in the latest research from Croatia and Turkey. In Croatia, the most used antibiotics are amoxicillin with clavulanic acid, amoxicillin, and clindamycin, respectively, according to studies by national health insurance data and cross-sectional selfreported study. ${ }^{20,21}$ Amoxicillin is part of the penicillin group of antibiotics, but is effective against a broader range of organisms and recommendations for antibiotic treatments in dentistry are to start with a narrower one (amoxicillin), so the broader one could be effective when needed. Observing these differences in results, with a great increase in amoxicillin with clavulanic acid, we may suggest that a shift has occurred in the first-choice antibiotic. It could be because of the differences in diagnosis and indications for antibiotic treatment. According to our study, the highest number of patients in health care dental clinics in 2015 to 2019 received antibiotics for maxilla-related health conditions, and the lowest number of them for oncologic ones. But further studies need to be done to confirm this observation.
The data in our research are based on the data of patients from secondary and tertiary health care facilities, with complex diagnoses, who are most often referred for treatment from primary health care institutions. Kosovo still has not implemented systemic monitoring of antibiotics utilization in primary dental health care, which presents a big problem in rationalizing antibiotics utilization in dental practice. The trends in antibiotics utilization in primary dental practice were partially illuminated by the Hailiti et $\mathrm{al}^{22}$ research, which required manually retrieving the data of each patient in 12 ordinations of primary dental practice. In primary dental offices where the study was conducted during March to June 2012, the most commonly prescribed antibiotic was amoxicillin with clavulanic acid (43.45\%), which followed by metronidazole (2.31 DDD) and amoxicillin (1.25 DDD). ${ }^{22}$ By comparing results, it is obvious that the rationalization in antibiotics utilization is more present in secondary/tertiary facilities than in primary health care. This can be primarily be seen from lower DDD values but secondarily from the first- 
choice antibiotic, amoxicillin against amoxicillin with clavulanic acid. The higher level of rationalization in tertiary care can possibly be explained by research, where dentists working in a university/hospital setting are more secure in making decisions regarding treatments and following protocols and accurate guidelines. $^{23}$

Regarding the dosage and duration of antibiotic therapy, the most prescribed antibiotic was $500 \mathrm{mg}$ of amoxicillin administered $3 \times 1$ for 5 days. The dosage and number of days are prescribed according to the clinical characteristics of patients. For cefazolin, the prescriptions were $3 \mathrm{~g}$ per os for 5 days, for cefalexin $1.5 \mathrm{~g}$ per os for 5 days, and for amoxiclav $1.5 \mathrm{~g}$ per os for 5 days as well. A similarity with the Croatian study was in the most common indication for antibiotics prescription, in Kosovo for KO4.7 (periapical abscess) without sinus and in Croatia for periapical or periodontal abscess, ${ }^{21}$ a fact which is similar also with findings of Palmer et al. ${ }^{24}$ This pattern of antibiotic prescribing is found to be accurate with the actual recommendations. But this result has to be confirmed with a further study determining prescription patterns for primary private dental health care, which are not part of clinics.

Although on a national level, a positive trend in rational prescription is observed, when analyzing each city separately, the case is different for each one. Regarding the scale of the rational use of antibiotics, in the case of Vushtrri, antibiotics were frequently prescribed for KO4.4 (acute apical periodontitis of pulpal origin), even though the clinical relevance of bacteria being present in the tissues is still not clearly defined in these infections. ${ }^{25}$ Regarding antibiotics prescriptions for KO4.1 (necrosis of the pulp) in FHCC V "Dardani," Prishtinë, these drugs cannot achieve an adequate therapeutic concentration within the necrotic pulp ${ }^{26}$ as well as are not needed in periapical infections because of meticulous endodontic technique use. ${ }^{27}$ In the Family Health Care Center IX "Vneshta," Prishtinë, antibiotics were frequently prescribed for KO4.2 (pulp degeneration) and some other studies have mentioned overprescription of these drugs in this case (irreversible pulpitis) ${ }^{28}$ In the Family Health Care Center 1, Prishtinë, the most common dental health condition for antibiotics prescription was also KO3.6 (deposits on teeth), which requires plaque removal and hygiene measures. In the Main Center of Family Medicine in Obiliq, the second most common dental condition for antibiotics' prescription was ZO1.2 (dental examination) even though antibiotics are not needed for simple dental examinations without defining a proper diagnosis. In the Main Center of Family Medicine in Hani i Elezit, KO4.0 (pulpitis) was the most frequent condition for antibiotics prescription by dentists, even though pulpitis is a clinical case, on which antibiotics are not needed. ${ }^{29}$ The treatment of pulpitis, as well as periapical periodontitis, requires only operative measures. ${ }^{30}$ Also, in Gjilan, KO4.5 was the most common dental condition treated with antibiotics, even though the routine use of systemic antibiotics in the treatment of chronic periodontitis is not justified in normal healthy patients because of the related risks. ${ }^{31}$ In these cases, the removal of the calculus and infected tissue by scaling and root planing procedure with irrigation removes the infectious foci and resolves the inflammation. ${ }^{25}$

There is currently a culture of antibiotic overuse in Kosovo, including attitudes and behaviors, and hence also experiences of patients, pharmacists, and physicians, which is possibly underlying the high consumption of antibiotics in the country. ${ }^{5,32}$ However, a level of awareness exists of the current problematic situation among practitioners and policy makers. ${ }^{5}$ In a study conducted in 2011 in Kosovo, antimicrobial use in 2011 was $26.3 \%$ DDD per 1,000 inhabitants per day and $56.8 \%$ of inpatients were using at least one antibiotic with ceftriaxone, as the most prescribed antibiotic, ${ }^{33}$ while data on antibiotic usage in dentistry to the date are unavailable. Previous studies have shown a high prescription rate of antibiotics in dental care in Kosovo. ${ }^{34,35}$ Most of the antibiotics prescriptions are empirical and use broad-spectrum antibiotics compared with narrow-spectrum ones. Although there are recommendations about antibiotic therapy in dentistry, there are no surveillance measures or research done to corroborate if dentists follow national policy measures and recommendations.

The limitation of the study is the lack of information on the prescription pattern from general and private dentistry practice, which would provide better insight into general antibiotic utilization from overall dentistry practice. The problem seems to be structural in nature; since the data collection method differs for each region and type of practice, many of them still uncategorized.

Based on the above findings, although there is an observed decreasing trend of antibiotic use in Kosovo on a national level in the years 2015 to 2019, many separate and smaller cities and places need improvement in antibiotic utilization. The decreasing trend is a positive result of the national antibiotic awareness program and should be continued and adjusted for observed differences. In the end, it can be stated, in light of the global dental health care standards, the irrational use of antibiotics in Kosovo remains a problem, which needs to be monitored and further addressed.

\section{Conclusion}

The results demonstrated that the patterns of antibiotics prescriptions by dental practitioners in Kosovo during the years 2015 to 2019 have an improving trend because fewer antibiotics have been used in secondary/tertiary dental clinics. Amoxicillin was the first-choice antibiotic as recommended, but co-amoxiclav utilization has shown a rapidly increasing trend which is a sign for alert and closer surveillance of antibiotic utilization in dentistry. Compared with the global health care standards, the irrational use of antibiotics in dental health care clinics in Kosovo still exist, and this issue should be further addressed by respective actors. There has been great inconsistency in prescribing patterns for different regions of Kosovo, which needs to be addressed in further investigations. Rational use of antibiotics in dental health care is imperative not only for dentists but also for pharmacists and patients. Kosovo and other Western Balkan countries need to review and/or fully align their national 
legal framework to enable effective implementation of EU legislation relating to AMR and EU standards; to set specific and measurable targets as a basis for national strategies and action plans and to have regular information updates on AMR and antimicrobial consumption available for proper monitoring against targets.

\section{Funding}

None.

\section{Conflict of Interest}

None declared.

\section{References}

1 Haque M, Sartelli M, Haque SZ. Dental infection and resistanceglobal health consequences. Dent J (Basel) 2019;7(01):22

2 Goossens $\mathrm{H}$. Antibiotic consumption and link to resistance. Clin Microbiol Infect 2009;15(Suppl 3):12-15

3 Raka L, Kurti A, Jakupi A, Krasniqi S, Turjaka A. Kosovo's national action plan for antimicrobial resistance. Lancet Infect Dis 2019;19 (03): 244

4 WHO. Central Asian and Eastern European surveillance of antimicrobial resistance: annual report 2017. Copenhagen: World Health Organization Regional Office for Europe; 2017

5 Jakupi A, Raka D, Kaae S, Sporrong SK. Culture of antibiotic use in Kosovo - an interview study with patients and health professionals. Pharm Pract (Granada) 2019;17(03):1540

6 Raka D, Versporten A, Hoti K, et al. The global point prevalence survey of antimicrobial consumption and resistance (global-PPS): results of antimicrobial prescribing in Kosovo hospitals. Paper presented at: 26th European Congress of Clinical Microbiology and Infectious Diseases; April 12, 2016; Amsterdam, Netherland. Accessed 2016 at: https://aricjournal.biomedcentral.com/articles/ 10.1186/s13756-020-00758-x

7 World Health Organization. Central Asian and Eastern European Surveillance of Antimicrobial Resistance. Annual Report. Accessed 2018 at: https://www.euro.who.int/en/health-topics/disease-prevention/antimicrobial-resistance/publications/2017/ central-asian-and-eastern-european-surveillance-of-antimicrobial-resistance.-annual-report-2017-2018

8 European Food Safety Authority, European Centre for Disease Prevention and Control. Regional workshop on a One-Health approach to antimicrobial resistance in EU pre-accession countries. ECDC (European Centre for Disease Prevention and Control) Meeting Report. Belgrade, Serbia: Regional workshop on a OneHealth approach to antimicrobial resistance in EU pre-accession countries. ECDC (European Centre for Disease Prevention and Control) Meeting Report. Accessed 2019 at: https://www.efsa. europa.eu/sites/default/files/event/190226-sc.pdf

9 Oliveira AS, Guerreiro MP. Influences on antibiotic prescribing by dentists: insights from a pilot study. Int J Clin Pharm 2015; 37:180

10 Cope A, Francis N, Wood F, Mann MK, Chestnutt IG. Systemic antibiotics for symptomatic apical periodontitis and acute apical abscess in adults. Cochrane Database Syst Rev 2014;26(06): CD010136

11 Segura-Egea JJ, Gould K, Şen BH, et al. European Society of Endodontology position statement: the use of antibiotics in endodontics. Int Endod J 2018;51(01):20-25

12 Addy M, Martin MV. Systemic antimicrobials in the treatment of chronic periodontal diseases: a dilemma. Oral Dis 2003;9 (Suppl 1):38-44
13 Ryalat S, Hassona Y, Al-Shayyab M, Abo-Ghosh M, Sawair F. Dentists' knowledge and practice regarding prevention of infective endocarditis. Eur J Dent 2016;10(04):480-485

14 Šutej I, Peroš K, Trkulja V, et al. The epidemiological and clinical features of odontogenic infective endocarditis. Eur J Clin Microbiol Infect Dis 2020;39(04):637-645

15 Habib G, Lancellotti P, Antunes MJ, et al; ESC Scientific Document Group. 2015 ESC Guidelines for the management of infective endocarditis: The Task Force for the Management of Infective Endocarditis of the European Society of Cardiology (ESC). Endorsed by: European Association for Cardio-Thoracic Surgery (EACTS), the European Association of Nuclear Medicine (EANM). Eur Heart J 2015;36(44):3075-3128

16 European Centre for Disease Prevention and Control. European Surveillance of Antimicrobial Consumption Network (ESAC-Net). Accessed April 2021 at: https://www.ecdc.europa.eu/en/about-us/ networks/disease-networks-and-laboratory-networks/esac-net-data

17 Versporten A, Bielicki J, Drapier N, Sharland M, Goossens HARPEC project group. The Worldwide Antibiotic Resistance and Prescribing in European Children (ARPEC) point prevalence survey: developing hospital-quality indicators of antibiotic prescribing for children. J Antimicrob Chemother 2016;71(04):1106-1117

18 Statistical Yearbook of the Republic of Kosovo. 2015 Prishtinë: Kosovo Agency of Statistics, 2015. Accessed April 2021 at: https:// ask.rks-gov.net/media/1303/statistical-yearbook-of-the-republic-of-kosovo-2015-08102015.pdf

19 Statistical Yearbook of the Republic of Kosovo. 2019 / the team that worked on the preparation of this yearbook: Isa Krasniqi. - Prishtina: Kosovo Agency of Statistics, 2019. Accessed April 2021 at: https://ask.rks-gov.net/media/5494/vjetari-2019_ang-final.pdf

20 Perić M, Perković I, Romić M, et al. The pattern of antibiotics prescribing by dental practitioners in Zagreb, Croatia. Cent Eur J Public Health 2015;23(02):107-113

21 Šutej I, Lepur D, Božić D, Pernarić K Medication prescribing practices in croatian dental offices and their contribution to national consumption. Int Dent J 2021:S0020-6539(21)00004-6

22 Haliti N, Krasniqi S, Begzati A, et al. Antibiotic prescription patterns in primary dental health care in Kosovo. J Family Med Prim Care 2017;19:128-133

23 Sutej I, Par M, Lepur D, et al. Dentists' practice and compliance with current guidelines of infective endocarditis prophylaxisNational survey study. J Clin Exp Dent 2021;13(07):e648-e652

24 Palmer NA, Dailey YM, Martin MV. Can audit improve antibiotic prescribing in general dental practice? Br Dent J 2001;191(05): 253-255

25 Ahmadi H, Ebrahimi A, Ahmadi F. Antibiotic therapy in dentistry. Int J Dent 2021;2021:6667624

26 Koyuncuoglu CZ, Aydin M, Kirmizi NI, et al. Rational use of medicine in dentistry: do dentists prescribe antibiotics in appropriate indications? Eur J Clin Pharmacol 2017;73(08):1027-1032

27 Alves Vde OEndodontic flare-ups: a prospective study. Oral Surg Oral Med Oral Pathol Oral Radiol Endod 2010;110(05):e68-e72

28 Stein K, Farmer J, Singhal S, Marra F, Sutherland S, Quiñonez C. The use and misuse of antibiotics in dentistry: a scoping review. J Am Dent Assoc 2018;149(10):869-884.e5

29 Salako NO, Rotimi VO, Adib SM, Al-Mutawa S. Pattern of antibiotic prescription in the management of oral diseases among dentists in Kuwait. J Dent 2004;32(07):503-509

30 Palmer NO, Martin MV, Pealing R, Ireland RS. An analysis of antibiotic prescriptions from general dental practitioners in England. J Antimicrob Chemother 2000;46(06):1033-1035

31 Teughels W, Feres M, Oud V, Martín C, Matesanz P, Herrera D. Adjunctive effect of systemic antimicrobials in periodontitis therapy: a systematic review and meta-analysis. J Clin Periodontol 2020;47(Suppl 22):257-281 
436 Systemic Antibiotics for Dental Treatment Mustafa et al.

32 Raka L, Spahija G, Gashi-Gecaj A, et al. Point prevalence survey of healthcare-associated infections and antimicrobial use in Kosovo hospitals. Infect Dis Rep 2019;11(01):7975

33 Versporten A, Bolokhovets G, Ghazaryan L, et al; WHO/EuropeESAC Project Group. Antibiotic use in eastern Europe: a crossnational database study in coordination with the WHO Regional Office for Europe. Lancet Infect Dis 2014;14(05): $381-387$
34 Ferech M, Coenen S, Malhotra-Kumar S, et al; ESAC Project Group. European Surveillance of Antimicrobial Consumption (ESAC): outpatient antibiotic use in Europe. J Antimicrob Chemother 2006;58(02):401-407

35 Haliti NR, Haliti FR, Koçani FK, et al. Surveillance of antibiotic and analgesic use in the Oral Surgery Department of the University Dentistry Clinical Center of Kosovo. Ther Clin Risk Manag 2015; 11:1497-1503 